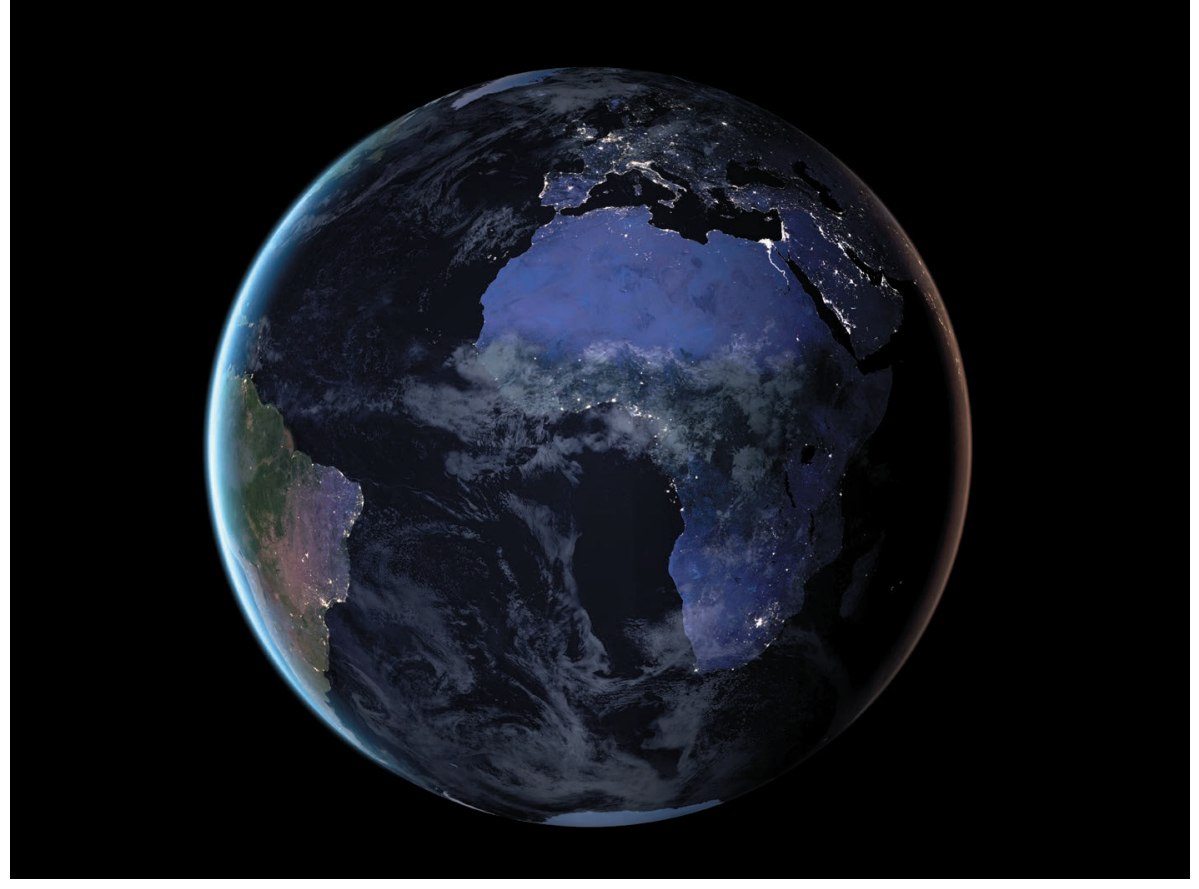

Al algorithms can compare night-time and day-time satellite images to measure levels of poverty.

\title{
AI summit aims to help world's poorest
}

\section{UNhopes to focus artificial intelligence on global good.}

\section{BY DECLAN BUTLER}

I $\mathrm{n}$ the world's wealthiest neighbourhoods, artificial intelligence (AI) systems are starting to steer self-driving cars down the streets, and homeowners are giving orders to their smart voice-controlled speakers. But the AI revolution has yet to offer much help to the 3 billion people globally who live in poverty.

That discrepancy lies at the heart of a meeting in Geneva, Switzerland, on 7-9 June, grandly titled the AI for Good Global Summit. The meeting of United Nations agencies, AI experts, policymakers and industrialists will discuss how AI and robotics might be guided to address humanity's most enduring problems, such as poverty, malnutrition and inequality.

Development agencies are buzzing with ideas, although only a few have reached the stage of pilot experiments. But scientists caution that the rise of AI will also bring societal disruption that will be hard to foresee or manage, and that could harm the world's most disadvantaged. "Developing countries may have the most to gain from AI, but also the most to lose if we are not vigilant," says Chaesub Lee, director of the Telecommunication Standardization Bureau of the UN's International Telecommunications Union, which is organizing the meeting.

Many researchers expect that AI systems will help to assess and track measures to alleviate poverty. At present, there are few accurate data on where the poorest people live because household surveys are infrequently carried out in poor or remote areas, says Marshall Burke, an economist at Stanford University in California.

Burke and his colleagues are training algorithms using night-time satellite images (in which well-lit areas are a rough proxy for affluence) to learn which features in daytime satellite images - such as roads, or roof types - correlate with relative wealth

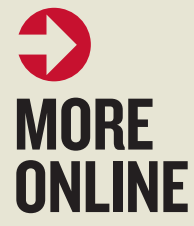

\section{STAY CURRENT}

- Next-generation cancer drugs boost immunotherapy responses go.nature.com/2qspahy

- How scientists reacted to the

US leaving the Paris climate accord go.nature.com/2sbw4m2

- Reef fish suck up meals with slimy lips go.nature.com/2rzmcy6

\section{MORE NEWS}

- Neuroscientists rethink how the brain recognizes faces go.nature.com/2s00vqy

- Pay-to-view journal blacklist set to launch go.nature.com/2szl446 - Web of Science owner buys up booming peer-review platform go.nature.com/2rzwOlh 
or poverty. In a pilot study in five African nations, the team found that its AI system predicts village-level wealth better than do earlier methods that use night lights alone.

Other scientists at Stanford, led by Jiaxuan You, are using AI and satellite remote-sensing data to predict crop yields months ahead of harvest, hoping to anticipate food shortages. And the UN children's charity UNICEF is investing in work to test whether deep learning can diagnose malnutrition from photographs and videos of children. "This is currently done using mid-upper-arm circumference and is slow and not always super-accurate," says Christopher Fabian, the head of UNICEF's innovation and venture funding unit. "We believe we can do better."

AI has been used for years in responses to natural disasters: helping to track where casualties and relief needs are greatest by parsing social-media messages and analysing satellite and drone imagery. In 2016, the XPRIZE Foundation, based in Culver City, California - which is co-organizing the Geneva summit — announced a US\$5million prize fund to reward ideas for using AI to solve challenges facing society.

But just as the Internet has brought risks and rewards that few could have anticipated, so AI will have "good, bad, transformative and plain weird effects" on societies, says Anders Sandberg, who studies the societal and ethical issues of new technologies at the University of Oxford, UK. The Geneva summit, for instance, focuses on how AI could help to achieve the UN's Sustainable Development Goals - targets to improve the lives of the world's poorest people by 2030. One is to ensure decent jobs for all. Yet a 2016 report from financial institution Citi suggests that AI and robotics might hit jobs in developing countries hardest.

Concerns over some of these risks have prompted industry to fund initiatives focused on societal benefit. They include OpenAI - a non-profit research company launched in December 2015 with $\$ 1$ billion of funding from philanthropists and entrepreneurs, in part to develop 'safe' AI systems - and the Partnership on Artificial Intelligence to Benefit People and Society, founded last October. The partnership includes Google, Microsoft and Facebook, but also UNICEF, Human Rights Watch and a host of non-profit organizations; in May, it announced that it would launch a grand-challenge series to boost initiatives that use AI to address long-term societal issues.

Ultimately, it is the firms developing AI that will have the greatest say in the technology's future direction, warns Milton Mueller, an expert on Internet governance at the Georgia Institute of Technology in Atlanta.

\section{Romanian science reforms spur boycott} Government blocks international scientists from panels.

\section{BY INGA VESPER}

$\mathrm{R}$ esearchers in Romania are stepping up protests against controversial government science reforms. Hundreds of scientists at leading research institutions say they will refuse to sit on national panels that assess and award grants, after the Romanian researchers' association Ad Astra called for the boycott on 30 May. But not all scientists in the country support the move.

Since Romania's current government took power in January, it has replaced formerly independent research councils with state-controlled bodies and has thrown international scientists off review panels. Panels can now only use international scientists to help select grants if no Romanian expert can be found - and even then, only if government officials approve it.

The government has told Romanian media that the changes are to help "capitalize on Romania's national potential". But researchers say that they are the latest in a series of policy backslides, whereby Romania - which this year celebrates a decade in the European Union - is retreating from international scrutiny of its research funding, and reintroducing political interference into the grant process.

"It is inconceivable for an EU country to intentionally forbid European expert evaluators to participate in national competitions for funding research," says Daniel David, vice-rector for competitiveness at Romania's Babeș-Bolyai University in Cluj-Napoca. "Just by this decision, researcher competition gets under political influence," he says.

\section{PAPERS PLEASE}

Last month, Romania's government said that scientists had to provide certificates showing that they have their university's permission to participate in the evaluation process. Officially, this is to provide confirmation of a researcher's work status at their organization - but Ad Astra sees the paperwork as a government ploy to approve only researchers who won't be too critical of grant applications. Its boycott asks researchers not to provide the certificates. "The degradation of research management in Romania has reached a worrisome level," says Ad Astra member Lucian Ancu, who adds that he has received many messages of support for the boycott. The Romanian research ministry did not respond to requests for comment.
After Romania joined the EU in 2007, its government hoped to encourage local scientists to apply for excellence-based European research funds. In 2010, the government introduced laws to increase domestic merit-based research assessments and reduce political interference in grants. Those policies were popular with the most capable scientists at top universities, says Daniel Funeriu, Romania's research and education minister from 2009 to 2012. But others resented them, he says.

In 2012, some of the reforms were rolled back, and the latest moves to exclude overseas experts effectively complete the reversal of these policies, says Funeriu. The government can now decide who gets grants according to its

"It is inconceivable
for an EU country
to intentionally
forbid European
expert
evaluators."
own set of priorities, he says, adding that the risk, he notes, is that money is distributed to a political clientele and not to excellent science.

The European University Association (EUA) in Brussels says that it deplores the research changes. On 30 May, it issued a statement calling them a "worrying development". The number of nationally funded projects has dropped, and researchers say that calls for excellencebased grants have been shelved, adds Lesley Wilson, the EUA's secretary-general. She notes that the reforms are part of a long chain of policy changes, which together "do not allow universities to develop long-term strategies".

But not all scientists in Romania support the boycott. "A lot of people were really hurt by the meritocratic system, so they like the status quo," says Costin Raiciu, a computer scientist at the University Politehnica of Bucharest. The boycotting scientists pledge that they will rejoin the approval process only when international experts are re-admitted. But the reforms might not be reversed, owing to the split between academics inside Romania, Ancu and Raiciu say. If they are not rolled back, Raiciu worries that many of the country's experienced researchers, tempted back to Romania by the merit-based grant system, will leave again. "Without [meritbased] funding, people would either give up research altogether or move out of the country," he says. 